concepts to fibres and yarns and the engineering improvement of the spinning process. He is the author of a number of scientific papers on physical and engineering subjects, a Fellow of the Institute of Physics and has for many years played an active part in the development of technological education. The new Research Association is to be congratulated on getting as its first director a man of outstanding scientific ability, who brings to it also an appreciation of the problems of industry, and particularly of engineering industry, at a time when the machine tool industry in Britain looks to be moving into a new phase of production techniques.

\section{Pure Mathematics at Swansea :}

Prof. R. Wilson

Prof. R. Wilson, head of the Department of Pure Mathematics in Swansea, retires in September 1961 after being a member of the steff of the University College of Swansea (University of Wales) for forty years. Educated at Bradford Grammar Sohool and Queen's College, Oxford, where he was a Hastings Scholar, he served in the First World War before graduating in 1921. In the same yoar he was appointed an assistant lecturer in the Department of Mathematics in Swansea, a year after the foundation of the College. He became a senior lecturer in 1929 and professor from 1942. His published research papers cover a variety of topics in mathematical analysis and those on the classification of singularities of functions of a complex variable are perhaps best known. He spent a year in Cambridge as a Leverhulme Research Fellow during 1938-39, and in 1955 was awarded an Oxford D.Sc. Three times dean of the Faculty of Science, and for his last five years the senior professor in Swansea, Prof. Wilson has served at one time or another on a large number of the committees of the College and of the University of Wales, and has often provided a powerful stabiliz. ing influence, in days of rapid expansion and frequent change, using his long experience to help preserve continuity with the earliest days of the youngest of the Welsh university colleges.

Prof. J. D. Weston

DR. J. D. WestoN, reader in mathematical analysis in the University of Durham at King's College, Newcastle upon Tyne, has been appointed to succeed Prof. Wilson. Among his responsibilities will be that of organizing all the post-intermediate teaching of mathematics to applied scientists in the College, and it is of interest in this connexion that Prof. Weston first graduated by taking a first-class honours degree in engineoring in London in 1939. As a practising radio development engineer, he was on the staff of Standard Telephones and Cables, Ltd. After gaining a London B.Sc. in mathematics (1944) and Ph.D. in engineering (1946), he was for a short time lecturer in mathematics at the Woolwich Polytechnic and later lecturer in the Mathematics Department of the University of Sheffield until 1949. He then moved to King's College, Newcastle, where he became a senior lecturer in 1958 and was appointed to a personal readership in 1960 . During the academic year 1959-60, he hold a visiting associate professorship in the California Institute of Technology, and in 1960 was awarded a London D.Sc. Prof. Weston has a distinguished research record and an international reputation as a functional analyst. His published work has been concerned mainly with the properties of certain topological spaces, including linear spaces, and more recently with an elegant treatment, based on convolution algebra, of that part of distribution theory from which a rigorous account of the Heaviside operational calculus can be developed.

\section{Re-organization in the U.K. Atomic Energy Authority}

Changes in the organization of the United Kingdom Atomic Energy Authority are being made, as the result of recommendations of the Select Committee on the Industrial Group which reported in July 1959. Sir William Penney has been appointed deputy chairman, with primary responsibility for scientific and technical co-ordination throughout the Authority. The work of designing and developing nuclear reactors will be concentrated, to the greatest possible extent, in one group of the Authority. The major development facilities required for this purpose will be under its control. The structure of the Development and Engineering Group will be modified for this purpose. It will be re-named the Reactor Group and will be responsible for the design and development of reactors, and for relations in this field with industry in Great Britain and with overseas countries. The Winfrith Research Establishment, which has responsibilities in the same field, will be transferred from the Research Group to the Reactor Group. The existing responsibilities of the Development and Engineering Group for the design and construction of plant, works and buildings will be transferred to a new Engineering Group, which will also take over from the Production Group its responsibilities for the design and inspection of fuel elements for production purposes. Apart from the transfer of the Winfrith Research Establishment, the structure and responsibilities of the Research Group remain unchanged. The Weapons Group is unaffected by the new arrangements.

\section{National Lending Library for Science and Tech- nology}

In a written answer in the House of Commons on February 16, the Parliamentary Secretary for Science, Mr. D. Freeth, said that from April 1957 until the end of March 1961, expenditure on the National Lending Library for Science and Technology was estimated at $£ 904,000$, including the capital cost of adapting the buildings at Boston Spa, Yorkshire. The net cost of the existing Library unit in London would be about $£ 272,000$ in the current financial year, and after the move to Boston Spa was completed and the Library was fully operational, at the end of 1962, the annual cost would be about $£ 315,000$. No direct expenditure had yet been incurred on the National Reference Library for Science and Invention.

\section{The Health Programme in India}

THE November issue of Science and Culture (26, No. 5) contains an article outlining the health programme of the Third Five Year Plan in India, and also a discussion of the proposals by Dr. A. N. Khosla, delivered to the Health Panel of the Planning Commission. Of the $\mathbf{3 0 0}$ crores of rupees allocated for health, 80 crores are for water supply and sanitation, 50 crores for primary health units, hospitals and dispensaries, 92 crores for control of communicable disenses, 38 crores for education and training and 25 crores for family planning. The shortage of medical personnel is a grave problem; there are 